\title{
ENTREVISTA
}

\section{Uma conversa com Gilles Fauconnier ${ }^{1}$}

Carla Viana Coscarelli

Universidade Federal de Minas Gerais

\section{Carla: Você poderia me dizer o que é a Teoria dos Espaços Mentais?}

Fauconnier: Grande parte do trabalho sobre espaços mentais trata do que acontece nos bastidores da cognição. Em outras palavras, trata do que acontece em nossas mentes, dos processos que não podemos ver ou ouvir. Espaços mentais se referem ao que acontece por detrás das cenas quando falamos ou pensamos; são construções mentais muito complexas, até mesmo para as sentenças mais corriqueiras. São pequenos conjuntos de memória de trabalho que construímos enquanto pensamos e falamos. Nós conectamos esses espaços entre si e também os relacionamos a conhecimentos mais estáveis. Muitas evidências para essas atividades mentais implícitas e para as conexões dos espaços mentais são fornecidas através de conhecimentos lingüísticos e gramaticais.

\section{Carla: O que exatamente é um espaço mental?}

Fauconnier: É difícil definir um espaço mental abstratamente, sem o uso de exemplos e sem um contexto mais completo. Até onde podemos dizer, os espaços mentais são, provavelmente, ativações que são estabelecidas no cérebro, na memória de trabalho. Provavelmente nós os organizamos e os conectamos através de excitações sincrônicas de conjuntos de neurônios. Mas isso são suposições, uma vez que ninguém, de fato, pode ver os espaços mentais no cérebro. Portanto, eles são definidos como um tipo de descrição de alto nível, baseada

\footnotetext{
${ }^{1}$ Entrevista gravada em vídeo na University of California at San Diego em abril de 2004. Transcrita e traduzida por Arabela Franco e Carla V. Coscarelli.

${ }^{2}$ Agradeço o apoio da CAPES, processo BEX 0418/04-8.
} 
em generalizações e que nos permitem explicar ou formular hipóteses sobre a linguagem, sobre a gramática ou sobre o pensamento.

\section{Carla: Qual o seu exemplo favorito de espaços mentais?}

Fauconnier: As piadas são meus exemplos favoritos. Não considero o exemplo que darei aqui como simples ou elementar para explicar os espaços mentais, pois ele envolve elementos contrafactuais e metáforas. É uma piada sobre o presidente Bill Clinton, sobre como ele pôde ter tido sua popularidade aumentada apesar de ter sido atacado pelos mais variados tipos de inimigos. Todos pensavam que ele estaria em apuros, mas, na realidade, o que aconteceu foi que ele estava ficando cada vez mais popular. Então, naquele momento, as pessoas costumavam dizer que "se Clinton fosse o Titanic, o iceberg é que teria afundado".

Clinton foi então comparado ao Titanic; e o Titanic, quando era o Clinton, era tão forte que, ao chocar-se com o iceberg, este é que afundaria, contrariando assim as leis da física.

Para a compreensão dessa piada, temos de abrir um espaço mental do iceberg e do Titanic, no qual nós sabemos o que é o Titanic: um navio enorme que afundou. Temos de construir também um outro espaço mental com o conhecimento que temos sobre o Clinton e sobre todos os ataques que ele sofreu. A partir desses dois espaços mentais, temos de construir um terceiro. Agora temos uma espécie de ClintonTitanic tão forte que é capaz de afundar um iceberg. Esse é, portanto, um exemplo do que geralmente fazemos quando contamos uma piada ou quando conversamos.

\section{Carla: O que há de novo no livro The Way We Think, que você escreveu com Mark Turner, em comparação com os seus outros livros?}

Fauconnier: Nós chamamos a atenção no livro The Way We Think para uma operação cognitiva fundamental para os seres humanos: a capacidade de agrupar diversos espaços mentais e, a partir desse agrupamento, criar novos espaços mentais que possuem uma estrutura emergente. Os seres humanos, em particular, parecem capazes do que chamamos de "integrações de duplo escopo", em que espaços mentais conflitantes são introduzidos. A partir dessa integração de espaços podem surgir novas estruturas muito criativas. Argumentamos 
indiretamente que essa capacidade de fazer mesclas duplas pode, de fato, ser o que caracteriza as capacidades cognitivas de nossa espécie. É ela que nos permite fazer coisas tais como arte, ferramentas, ciência e linguagem, habilidades que outras espécies não parecem possuir. Essas habilidades são relativamente recentes, mesmo na evolução biológica de espécies semelhantes à do homem. Elas provavelmente surgiram por volta de 50, 60 ou 70 mil anos atrás e parece que todas surgiram ao mesmo tempo. Nós especulamos que isso possa estar relacionado à capacidade de fazer integrações conceituais de formas mirabolantes como, por exemplo, no nível das "integrações de escopo duplo". É isso que se difere nesse livro. Nos outros, as reflexões sobre os espaços mentais não tinham, na verdade, realmente descoberto que, além de estabelecer os espaços mentais, conectá-los e transferi-los, projetando as estruturas de uns para outros, havia também esse outro aspecto defendido no livro, segundo o qual se podem criar espaços mentais à medida que se avança, e essa é uma atividade cognitiva muito importante. Isso é a grande diferença.

O livro The Way We Think é o resultado de 6 ou 7 anos de trabalho com Mark Turner e com outras pessoas que se interessaram pela teoria da mesclagem dos espaços mentais. No ano em que o livro foi escrito, nós percebemos algo da teoria de mesclagem que, até então, não tínhamos notado. Vimos que as projeções entre os espaços mentais usadas para criar redes são, na realidade, muito ricas e podem ser de diferentes tipos. Descobrimos que elas parecem pertencer a um conjunto de projeções de relações vitais e que são de certa forma muito importantes para os seres humanos. Relações vitais incluem coisas do tipo: causa e efeito, mudança, identidade, tempo, espaço, entre outras. Existe aproximadamente uma dúzia de diferenças e semelhanças e há em torno de 15 ou 16 relações vitais. Nossa grande descoberta é que uma das funções das mesclagens e da criação dessas elaboradas redes conceituais é possibilitar a compreensão de relações vitais. São compressões muito sistemáticas, de forma que podemos comprimir o que chamamos de espaço externo ou interno, ou podemos tomar emprestadas compressões já existentes, com a finalidade de criarmos novas mesclas. É o resultado dessas compressões que torna as coisas mais acessíveis, mais inteligíveis, e mais fáceis de serem manipuladas pelos seres humanos. 
O exemplo do Clinton e do Titanic é um bom exemplo de compressão, porque o que estamos falando naquela história é, na verdade, algo complexo e difuso. Há muitos atores, muitos políticos e muitas intrigas envolvidas. O próprio Clinton teve muitas aventuras de diversos tipos, por isso essa é uma história complexa, difusa e difícil de entender. Da maneira como a história é contada, em termos da possibilidade contrafactual de o Titanic afundar o iceberg, o que acontece é que os eventos são comprimidos em uma história bem mais simples, com a redução de muitos atores e de muitos objetos. A própria história também foi comprimida - a relação causa-efeito foi reduzida a um único evento numa escala humana no qual surgem o Titanic e o iceberg, e um colide com outro causando, então, imediatamente, o afundamento de um deles. Esse é o resultado das possibilidades de compressão que deixamos passar desapercebido nos trabalhos anteriores sobre espaços mentais e mesclagem.

\section{Carla: Como a Teoria de Espaços Mentais lida com ou se encaixa na idéia tradicional dos domínios de processamentos? Eu poderia dizer que os Espaços Mentais são compativeis com o conexionismo ou qualquer outra visão sobre a compreensão?}

Fauconnier: O nível de descrição que estamos tratando está sendo expresso em termos de processamento em um nível relativamente elevado, isto é, nós descrevemos o pensamento e a linguagem como de fato estabelecendo esses espaços, encontrando conexões entre eles e construindo novos espaços. Nesse sentido, podemos dizer que é um modelo de processamento de noções cognitivas de níveis superiores.

Agora, quando se fala em processamento nas Ciências Cognitivas e na Psicologia, normalmente refere-se a níveis mais inferiores de processamento. Na realidade, uma das atuais ambições é explicar níveis bem inferiores de processamento que estariam no nível neuronal. Os psicólogos têm normalmente tratado dos níveis de processamento um pouco mais elevados e querem saber, por exemplo, o que é que as pessoas estão integrando em um dado momento, o que se passa a cada milésimo de segundo. Contudo, não é isso que interessa à teoria dos espaços mentais. Precisamos nos referir a esse tipo de questão e integrar os insights sobre os espaços mentais e, para isso, precisamos de uma teoria psicológica sobre como o sentido é processado, incluindo as 
conexões dos espaços mentais, etc. Portanto, essas coisas são bem distintas, porque a abordagem da teoria dos espaços mentais não é simbólica, não é sobre a manipulação de algum tipo de linguagem do pensamento ou alguma coisa semelhante. Não é manipulação de símbolos na mente como o sistema lógico faria. Em vez disso, construímos espaços cognitivos elaborados que incluem muita informação visual, informações imaginativas, e daí por diante. Conseqüentemente, esse é um tipo de processo bem distinto. Nesse sentido, o processamento certamente não corresponderia ao processamento simbólico do tipo que decompõe símbolos.

A teoria dos espaços mentais é certamente compatível com as visões conexionistas, mas neste momento podemos especular que o processamento no cérebro é provavelmente muito mais complexo do que propõe qualquer sistema conexionista que temos visto. Para os espaços mentais em particular, precisamos ter conexões múltiplas entre espaços mentais, e também precisamos ter estruturas emergentes surgindo dessas múltiplas ligações. E isso não é algo que emergiria naturalmente em abordagens conexionistas. Portanto, em qualquer evento, os sistemas de processamento precisariam ser consideravelmente enriquecidos para lidar com o fenômeno dos espaços mentais ou fenômenos que envolvem analogia. Há várias propostas de modelos de analogia, e isso tem provado ser extremamente difícil - parece estar além das capacidades dos atuais modelos de processamento. Há também trabalhos tentando modelar coisas como mesclagens conceituais, e isso tem sido ainda mais difícil.

\section{Carla: O que você poderia me dizer sobre a relação entre Espaços Mentais e Enunciação?}

Fauconnier: Eu não tenho nada específico a dizer a respeito dessa relação, exceto por um embasamento comum que é o de não ver a linguagem como formas sintáticas estáticas que são logicamente interpretadas em sistemas semânticos, e que ambas consideram extremamente importante a dinâmica completa da situação comunicacional, como também o fato de que nas situações enunciativas nós nos adaptamos à medida que o discurso se desdobra dinamicamente. Nesse sentido, uma das coisas que podemos dizer é que os espaços mentais incorporam as situações enunciativas do falante, do ouvinte, do narrador e assim por diante. 
Outra coisa que é bem conhecida a princípio, e que também se manifestou naturalmente no trabalho sobre espaços mentais, é que a perspectiva e o ponto de vista são extremamente importantes para entender a linguagem. Isso também é verdade em outras áreas da semântica cognitiva como, por exemplo, no trabalho de Langacker sobre gramática cognitiva, ou no trabalho de Talmy em semântica cognitiva, em que há fortes componentes de perspectiva e ponto de vista. Na teoria dos espaços mentais isso é incorporado - o que torna possível a mudança de um espaço mental para um outro. Assim, um deles é tomado como foco, e o outro como ponto de vista, e outro, por exemplo, como uma base ou ponto de partida. Dessa forma, enquanto você pensa ou fala, você está metaforicamente se movendo de um espaço mental para um outro, e mudando de pontos de vista e de perspectivas. Acredito que isso seria compatível e harmonioso com várias teorias da enunciação, em oposição a outras teorias que só vêem formas estáticas e interpretações lógicas. Também é compatível com a idéia geral de que a linguagem em si mesma não nos diz muito a respeito do significado. Isso nos dá pistas sobre como construir significados quando nos encontramos em determinado contexto, em determinadas situações, usando nossas imensas capacidades cognitivas, mas também buscando muitas informações sobre o contexto e a situação. E mais, utilizamos toda uma gama de âncoras materiais que podemos captar das outras pessoas, falantes, ouvintes, objetos, etc. De fato, a linguagem nos propicia construir esquemas de mapeamento e as nossas habilidades de criar espaços mentais nos permitem construílos de uma determinada maneira.

\section{Carla: Qual a diferença entre os espaços genéricos eframes? Que tipo de coisa podemos esperar encontrar em um frame?}

Fauconnier: Alguns de vocês provavelmente sabem mais do que outros sobre a teoria da mesclagem conceitual. Uma das coisas que ela tipicamente inclui quando construímos redes é que há partes em comum do input que irá se mesclar. Portanto, há coisas em comum que são tipicamente representadas na teoria por um espaço mental genérico que pode, em si mesmo, ser manipulado em alguns casos.

O que isso quer dizer é que espaços genéricos contêm coisas que são comuns ao input. No meu exemplo do Clinton, o espaço genérico seria um exemplo bem esquemático porque ele tem a ver com algum 
tipo de colisão num sentido bem abstrato, que poderia ser concreto no caso de dois objetos - a colisão do Titanic com o iceberg. Poderia também ser social, como no caso de pessoas tentarem o impeachment do presidente, e daí por diante. Contudo, nesse exemplo, o espaço genérico é realmente muito abstrato. De fato, tão abstrato que nem chega a ser um frame identificável. Mas em outros casos, o espaço genérico pode até ser bem concreto, como no exemplo de uma corrida de barcos, no qual a mesclagem é formada pelas jornadas de dois barcos diferentes que se mesclam em uma única jornada, na qual os barcos competem entre si. Nesse exemplo, o que há de comum a esses dois eventos com relação ao espaço genérico é uma jornada que parte de um ponto específico, no caso a cidade de São Francisco, para uma outra cidade, Boston. Esse não é um frame geral. Esse é um caso específico de uma viagem de barco. Portanto, estamos nos referindo a alguma coisa que está entre um frame e eventos mais específicos. $\mathrm{O}$ genérico não se relaciona tanto com frames em geral quanto se relaciona com o input. O genérico é normalmente um pouco menos específico que o input. Algumas vezes ele é muito menos específico, já que carrega o que há de comum entre o input. Por isso é que ele é menos específico. Em muitos exemplos, o genérico é apenas o frame que você percebe, pois normalmente é o que acontece quando já existe um frame comum para o input. Portanto, o genérico terá esse frame em si mesmo.

\section{Carla: Como os 3 Is -Identificação, Imaginação e Integração funcionam?}

Fauconnier: No capítulo introdutório do livro The Way We Think, nós falamos sobre os 3 Is da mente. Em inglês, isso é um jogo de palavras, porque a letra $I$ realiza-se fonologicamente da mesma forma como a palavra que significa olho: EYE /aI/. Com isso, /aI/ pode ser o olho com o qual nós vemos, como também pode ser a representação das letras iniciais de cada uma das palavras Identificação, Integração Imaginação. O nosso livro direciona para a idéia de que, de fato, atividades mentais humanas muito complexas são realizadas nesses 3 Is.

Os 3 Is referem-se à Identificação no mesmo sentido em que a teoria dos espaços mentais se referia desde o início. Nós temos que ser capazes de conectar elementos entre os espaços mentais, ainda que 
esses elementos sejam completamente diferentes em termos de suas propriedades. Mais uma vez, no meu exemplo do Clinton, nós temos que ser capazes de conectar o Titanic e o Clinton. Temos de identificar esses dois elementos, o indivíduo e o navio, mesmo não havendo nenhuma analogia de qualquer natureza entre eles. Esse é um produto da nossa atividade mental. Também é um produto da nossa Imaginação. Para que tenhamos Clinton-Titanic afundando o iceberg, nós temos que imaginar uma cena fantástica. Lembramos que a imaginação está na raiz da maior parte das coisas que fazemos. Está na raiz do ato de contar histórias, da ficção, da produção de filmes, do fato de termos idéias, de nos perguntarmos o que vamos fazer com nossos amigos. A imaginação está também na raíz dos grandes avanços científicos a teoria da Relatividade de Einstein é um grande exemplo.

A peça central dessa faculdade da imaginação dos homens é a capacidade para a integração conceitual avançada, e as mesclagens conceptuais de duplo escopo, em particular, são um dos motores da imaginação. É uma das coisas que faz a imaginação humana tão perceptível para nós, mas também, certamente, muito mais notável para o resto do mundo, no sentido de que da nossa imaginação, para bem ou para mal, surgem todos os tipos de coisas. O mundo é diferente porque a partir das integrações que fazemos, acabamos por mudá-lo em vários sentidos.

Carla: O que é inferência? Faz sentido falarmos sobre inferências, considerando os espaços mentais e as mesclagens? Não seriam todas as construções de significado essencialmente inferenciais? E nesse raciocínio, faz sentindo falarmos em metáforas?

Fauconnier: Inferência é um termo da lógica que remete a Aristóteles e ao fato de haver padrões de pensamento. Portanto, tomemos a premissa "todos os homens são mortais" e, se "Sócrates é homem", você pode inferir que "ele é mortal". Isso é inferência em termos lógicos. É claro que nós fazemos muitas inferências sem que expliquemos, através da lógica, cada passo delas. Nós fazemos muitas inferências simplesmente porque nós temos padrões cognitivos muito complexos. Dessa forma, nós sabemos coisas sobre os frames que podemos chamar de inferências no sentido de que nós podemos inferi-las. Se, por exemplo, alguém sai pela porta deste escritório, nós inferimos que agora essa 
pessoa está do lado de fora do escritório. Ficaríamos surpresos se nós abríssemos a porta logo em seguida e essa pessoa tivesse desaparecido, ou se fôssemos informados de que ela agora está na Austrália. Nós inferimos que essa pessoa não está tão distante do escritório; e nós fazemos milhares de inferências desse tipo. Nós podemos chamar esses ricos sistemas de inferências de frames gerais do conbecimento, que são tanto as coisas que acontecem dentro dos frames quanto a forma como manipulamos esses frames.

Um componente importante desse sistema de inferências no momento em que ele acontece é a habilidade de projetarmos inferências que são válidas em um espaço mental em um outro espaço, como acontece nas analogias em geral ou em espaços mesclados nos quais você tem muitas inferências feitas a partir de determinado input. Essas inferências são, por sua vez, projetadas nos espaços mesclados. Mas, além disso, é por causa do fenômeno das estruturas emergentes que você terá uma estrutura emergente com seu próprio conjunto de propriedades. Isto é, surgirá uma estrutura com suas próprias propriedades inferenciais, dentro desse novo espaço mesclado. Dessa forma, seremos capazes de manipular essas estruturas emergentes nos espaços mesclados de maneira produtiva.

Tomando mais uma vez o exemplo do Titanic, a estrutura que emerge é a de que navios podem afundar icebergs. Sabemos que, de acordo com as leis da física, isso é impossível, porque icebergs não afundam, pois são mais leves que a água. Mas nos espaços mesclados a estrutura emergente permite que o iceberg afunde. Portanto, sabemos como manipular essa estrutura, mesmo sendo ela impossivel. Agora, em particular, sabemos como o iceberg afundou; sabemos que o Titanic ainda está seguindo sua jornada, indo em direção ao seu destino, e é ainda bem-sucedido.

Qual a relevância disso tudo? Bem, nós agora podemos projetar tudo isso. Nessas inferências engraçadas que fomos capazes de manipular, no espaço mesclado, o Titanic ainda está em seu curso, na direção certa, de maneira esplêndida; e o pobre iceberg está agora no fundo do oceano. Nós projetamos isso no espaço do qual estamos falando. Em outras palavras, Clinton está se saindo muito bem: ainda é o presidente, não sofreu o impeachment, e seus inimigos pediram demissão e caíram. É por isso que o sistema inferencial é tão forte; é 
aí que a estrutura da imaginação é capaz de combinar com o sistema inferencial. Assim, ao imaginar - ainda que sejam coisas fantásticas como esse exemplo do iceberg - nós podemos utilizar sistemas de inferências bem sólidos, a fim de projetarmos inferências de volta para o que esperamos que seja respondido.

Metáforas? Essa é uma questão interessante. Não seria tudo metáfora? Não seria tudo inferência? Não seria tudo mesclagem e daí por diante? De algum modo sim, isso é verdade! Porém, não há nada de errado com isso. Você também pode dizer "tudo é molécula!" Contudo, isso por si só não explica o mundo. Dizer que tudo é molécula apenas nos abre um vasto programa de pesquisa que pergunta: quais são elas? Como elas se combinam? Que tipos de moléculas existem? Esses questionamentos aparecem principalmente na Química e na Biologia. Longe das abordagens reducionistas que dizem que "tudo são moléculas, explicamos tudo", o fato de descobrir que tudo é molécula abre uma incrível gama de possibilidades de pesquisas. Com o trabalho a respeito das mesclagens, nós esperamos ter, pelo menos, começado algo similar, no sentido de que, longe de dizer que tudo se reduz a mesclagens ou a metáforas, dizemos o contrário: "veja a variedade de mesclagens que podemos ter!". Nós mostramos essa rica tipologia de redes de mesclagens; nós também apresentamos um rico conjunto de restrições, a que chamamos de princípios governantes e princípios constitutivos, para essas determinadas moléculas de significado.

\section{Carla: Você me contou que existem lacunas relacionadas com a forma como lidamos com as Ciências Sociais. Você poderia mencionar algumas dessas lacunas? Você me falou que quase ninguém estuda as crianças e as mesclas que elas fazem...}

Fauconnier: A ciência é em grande parte constituída de lacunas; da mesma forma são as Ciências Sociais. Há muitas coisas esperando para serem estudadas e descobertas. Quando nós falamos e estudamos sobre aprendizagem, fazemos experimentos psicológicos em crianças, gravamos dados sobre elas para ver o que é que aprendem, em qual estágio, em que idade, e daí por diante. Isso é inevitável e não é uma coisa ruim. É simplesmente um fato da ciência que você seja sempre prisioneiro de uma determinada abordagem teórica. Portanto, se você segue determinada linha teórica que enfatiza, por exemplo, a sintaxe 
formal, você vai estudar a maneira como aprendemos formas sintáticas. Você vai estudar muito da Psicolingüística, que tem a ver com questões do tipo: como as crianças aprendem transformações; como elas aprendem a fazer construções gramaticais complexas. Se você mudar para uma outra área como, por exemplo, a área do pensamento conceitual, você logo terá idéias de como poderá descobrir, por exemplo, quando as crianças aprendem a mentir. Quando de repente o seu foco muda, quando você está interessado em mentiras, você está interessado em como as crianças se projetam em outras pessoas, em determinadas teorias de outras mentes, como as pessoas interpretam o que a criança vai dizer, e daí por diante. Isso abre toda uma área de experimentos em Psicologia.

Quando se percebe a construção de muitos espaços mentais e, em particular, um grande número de mesclagens conceituais que acontecem bem cedo, antes mesmo de a linguagem se manifestar, é claro que se abre um outro campo muito vasto de estudo. Surgem questões do tipo: como as crianças estão aprendendo essas coisas? Quando isso se dá?

Parece inacreditável que essa área ainda não tinha recebido muita atenção. Há mesclagens muito complexas que vemos nossas crianças fazerem todo o tempo, por exemplo, ao brincarem "de faz de conta", ao montar a cavalo como cowboys, quando, na verdade, estão sentadas na cadeira da cozinha, talvez com uma colher na mão. Esses são comportamentos muito comuns das crianças, que nunca tiveram um lugar central nos estudos psicológicos, por incrível que pareça. Uma das razões foi que esse tipo de atividade foi tido pelos psicólogos como sendo muito trivial se comparado com uma atividade mais formal como a fala, o raciocínio lógico, o levantamento de premissas e conclusões. De certa forma, viramos a mesa quando dissemos que o que as crianças estão fazendo desde cedo, quando elas brincam de "faz de conta", são complexas mesclagens de duplo escopo. Isso por si só é muito mais difícil do que provas lógicas, porém com uma diferença: a prova lógica você faz explicitamente, de forma consciente, com as aplicações de regras que foram dadas a você. É claro que no caso de brincar de "faz de conta", as crianças o fazem inconscientemente. Isso não faz com que esse fato seja menos importante ou menos complexo. Isso abre uma área que demanda por experimentos psicológicos que não foram 
ainda feitos por razões muito naturais: apenas porque as questões não estavam lá para serem respondidas!

A Carla, que está me fazendo essas perguntas, nos mostrou aqui em San Diego alguns ótimos exemplos de crianças com três anos de idade fazendo construções de espaços mentais bem elaborados, que nós só podemos notar porque, em primeiro lugar, nós temos o conceito de construção de espaços mentais. Caso contrário, nós diríamos: "olha só, a criança está confusa. A criança está inventando um jogo bobinho! Não entende o que os adultos querem dizer!".

\section{Carla: Terminamos! Você gostaria de dizer mais alguma coisa?}

Fauconnier: Eu adoraria dizer muito mais coisas. Mas você tem que filmar! O que vocês estão vendo na tela é uma entrevista e o que eu estou vendo aqui é uma câmera que está sobre a mesa deste escritório. Em vez de ver as pessoas com quem eu estou falando, eu estou vendo esta câmera! Não há um exemplo de mesclagem conceitual tão poderoso quanto esta atividade na qual estamos envolvidos agora, porque eu estou literalmente sentado na frente da câmera e, ainda assim, reparem, eu estou conversando como se estivessem na minha frente (e sabe-se lá quem são vocês!). Converso como se nós estivéssemos interagindo. Quando pensamos sobre isso, percebemos que na verdade essa é uma construção fantástica da mente. Desde o começo desta entrevista, Carla e eu estamos manipulando espaços mentais elaborados. Nós manipulamos o espaço mental que corresponde a uma situação futura na qual ela vai mostrar esta fita para os colegas, alunos, ou a quem quer que seja. Então, como se fosse mágica, o que estou fazendo agora na frente desta pequena câmera vai ser percebido como se eu estivesse realmente falando para as pessoas que estão assistindo ao vídeo. Se pensarmos em fazer esse mesmo tipo de atividade com chimpanzés, lagartos, ou outros animais, isso não pareceria tão óbvio quanto nos parece.

A imaginação, como vocês podem notar, desempenha um papel crucial nesta entrevista em particular. Acho que entrevista (Interview em inglês) é o quarto " $I$ " /aI/, (risos). A identificação também exerce aqui um papel fundamental porque, ao olhar para a câmera, estou identificando os ouvintes ou os espectadores que tenho e, é claro, não faço idéia de quem sejam! Pelo que sei, a Carla está me pregando uma 
peça! Ela é uma espiã! Talvez as pessoas que irão assistir a este vídeo não sejam, na verdade, as pessoas que imaginei (risos). Talvez, todo o processo de identificação mais integração mais entrevista que eu estou construindo não tenha nada a ver com o que vai acontecer no futuro. Mas isso não tem importância, porque, em termos de construtos psicológicos produzidos sob o impulso do momento, isso é o que realmente está acontecendo na minha mente! Quem é que pode imaginar o que está se passando na mente da Carla?!

Carla: Women, fire and dangerous things! Obrigada, Fauconnier! 